\title{
BATAS MINIMAL MAHAR
}

(Kajian Komparasi Antara Pendapat Mazhab Hanafi Dan Mazhab Syafi'i)

Cumeda, Irfan Hasanudin, Mujahid

Prodi Akhwal Syakhsiyah, Fakultas Agama Islam, Universitas Nahdlatul Ulama Indonesia (UNUSIA)

E-mail: cumeda_unusia@gmail.com

Article Information

Informasi Artikel

Naskah diterima: 18 April

2019

Naskah direvisi: 20 Juni 2019

Naskah disetujui: 5 Juli 2019

Naskah dipublish: 5 Oktober 2019

Kata Kunci Mahar, Mazhab Syafii, Mazhab Hanafi

\section{Abstrak}

Mahar adalah pemberian wajib berupa uang atau barang dari seorang pria kepada wanita dengan sebab pernikahan atau hubungan seksual sebagai lambang kesungguhan dan tanggungjawab. Para ulama fiqh sepakat bahwa tidak ada batas maksimal mahar, tetapi mereka berbeda pendapat mengenai batas minimal mahar. Mazhab Hanafi berpendapat bahwa batas minimal mahar adalah 10 (sepuluh) dirham, sementara mazhab Syafi'i berpendapat mahar itu tidak ada batas minimalnya, bahkan ditegaskan bahwa apapun yang berharga atau dapat dijadikan harga bagi sesuatu atau upah boleh dijadikan mahar, yang penting dalam mahar itu adalah kerelaan istri. Penelitian dalam ini termasuk penelitian kepustakaan dan bersifat deskriptifkomparatif yang berupaya membandingkan dan menelusuri dasar hukum dan argumentasi antara pendapat fiqh Mazhab Hanafi dan Mazhab Syafi'i tentang batas minimal mahar. Pendapat Mazhab Hanafi yang menyatakan batas minimal mahar adalah sepuluh dirham berdasarkan hadits riwayat Imam Ad-Daraquthniy setelah dilakukan penelitian sederhana adalah hadits dha'if. Sementara Mazhab Syafi'i yang menyatakan bahwa mahar itu tidak dibatasi dengan nominal tertentu, tetapi segala sesuatu yang bernilai meskipun kecil sah dan dapat dijadikan mahar berargumen dengan hadits riwayat Imam Malik, Imam Syafi'i, Imam Bukhariy, Imam Muslim, Imam Abu Dawud dan Imam Tirmidzi.

\section{PENDAHULUAN}

Perkawinan mempunyai arti penting dalam kehidupan manusia. Dengan perkawinan yang sah, manusia dapat menyalurkan hasrat seksualnya dengan hidup berpasang-pasangan dan melestarikan kelangsungan hidup manusia. ${ }^{1}$ Setelah akad nikah dilangsungkan antara mempelai laki-laki dan mempelai perempuan yang dilakukan oleh walinya, terjalinlah hubungan suami istri dan timbul hak dan kewajiban

\footnotetext{
${ }^{1}$ Ahmad Azhar Ba syir, Hukum Perkawinan Islam, (Yogyakarta: UII Press, 1999), h 1. 
masing-masing secara timbal balik. Hak-hak dalam perkawinan itu dapat dibagi menjadi tiga yaitu hak bersama antara suami dan istri, hak istri yang menjadi kewajiban suami dan hak suami yang menjadi kewajiban istri. ${ }^{2}$

Dari paparan di atas, penulis dapat menyimpulkan bahwa perkawinan merupakan ikatan atau akad antara dua manusia berbeda jenis dengan niat menjalankan sunnah Rasul dan demi melestarikan keturunan dengan konsekuensi masing-masing pasangan memiliki hak dan tanggungjawab. Di antara kewajiban suami terhadap istrinya adalah mahar. Pemberian mahar oleh suami adalah lambang kesungguhan dan penghormatan suami terhadap istri. Pemberian mahar juga mencerminkan kasih sayang dan kesediaan suami untuk hidup bersama istri serta sanggup berkorban demi kesejahteraan rumah tangga dan keluarga. ${ }^{3}$ Di samping itu, mahar adalah simbol cinta dan kasih sayang dari calon suami kepada calon istri, bukan uang pengganti untuk memiliki si wanita tersebut, apalagi sebagai uang ganti untuk mendapatkan layanan. Karena itu, membayar mahar bukan berarti mendapatkan layanan. Suami dan istri adalah pasangan yang harus saling melayani dan dilayani. ${ }^{4}$

Dasar kewajiban mahar adalah firman Allah "Dan berikanlah para perempuan (yang kamu nikahi) itu mahar-mahar mereka sebagai pemberian dengan penuh kerelaan. Apabila mereka memberikan sebagian dari mahar mereka dengan kerelaan hati, maka makanlah (terimalah) pemberian itu (sebagai makanan) yang sedap lagi baik akibatnya."(QS. An-Nisa'/4:4) Dari terjemahan ayat al-Qur'an di atas dapat diperoleh suatu pengertian bahwa maskawin itu adalah harta pemberian wajib dari suami kepada istri, dan merupakan hak penuh bagi istri yang tidak boleh diganggu oleh suami, suami hanya dibenarkan ikut makan maskawin apabila diberikan oleh istri dengan sukarela. ${ }^{5}$

Ayat di atas juga merupakan bukti bahwa Al-Qur'an telah menghapus kebiasaan zaman jahiliyah mengenai mahar dan memulihkannya pada kedudukannya yang asasi. Di masa jahiliyah yakni zaman sebelum Islam, para ayah dan ibu yang mempunyai anak-anak gadis menganggap bahwa mahar adalah hak mereka sebagai imbalan atas susah payah mereka membesarkan dan merawat si anak. Tetapi dengan turunnya ayat

\footnotetext{
${ }^{2}$ Ibid., h. 53

${ }^{3}$ Firdaweri, Hukum Islam tentang Fasakh Perkawinan Karena Ketidakmampuan Suami Menunaikan Kewajibannya, (Ja karta: CV Pedoman Ilmu Ja ya, 1989), h. 14.

${ }^{4} 4$ Khoiruddin Na sution, Hukum Perkawinan I, (Yogya karta: Academia+Tazzafa, 2013), h. 179.

${ }^{5}$ Ahmad Azhar Basyir, Hukum Perkawinan Islam, h. 54. 
ini, jelaslah bahwa mahar adalah hak milik mempelai wanita, bukan milik ayah atau walinya. ${ }^{6}$

Senada dengan hal ini, Kompilasi Hukum Islam (KHI) Indonesia juga mengatur mahar secara panjang lebar dalam pasal-pasal 30, 31, 32, 33, 34, 35, 36, 37, dan 38. KHI pasal 30 misalnya menyatakan, "Calon mempelai pria wajib membayar mahar kepada calon mempelai wanita yang jumlah, bentuk dan jenisnya disepakati oleh kedua belah pihak". KHI dalam hal ini tidak membatasi mahar dengan nominal tertentu, yang ditekankan oleh KHI adalah kesepakatan kedua belah pihak tentang jumlah mahar baik sedikit maupun banyak. Selanjutnya, KHI juga menegaskan bahwa mahar adalah hak penuh istri pada pasal 32 yang berbunyi, "Mahar diberikan kepada calon mempelai wanita dan sejak itu menjadi hak pribadinya”. Selain itu, KHI juga menjelaskan bahwa mahar bukanlah rukun nikah sehingga apabila mahar tidak disebutkan dalam akad nikah, pernikahannya tetap sah. Pasal34 KHI menyebutkan: (1) Kewajiban penyerahan mahar bukan merupakan rukun dalam perkawinan. (2) Kelalaian menyebut jenis dan jumlah mahar pada waktu akad nikah tidak menyebabkan batalnya perkawinan. Begitu pula halnya dalam keadaan mahar masih terutang, tidak mengurangi sahnya perkawinan. ${ }^{7}$ Para ulama berkata bahwa mahar bukanlah rukun nikah seperti halnya barang yang dijual dan harga dalam jual-beli, karena tujuan yang paling tampak dalam perkawinan adalah hubungan intim. Meskipun mahar bukan rukun nikah, tetapi disunnahkan menyebut mahar dalam akad nikah agar terhindar dari perselisihan dan pertengkaran di kemudian hari. ${ }^{8}$

Terkait dengan nominal atau besar kecilnya mahar yang harus diberikan oleh suami tidak ada patokan atau standar yang harus dipenuhi. Para ulama fiqh sepakat bahwa tidak ada batas maksimal yang harus diberikan, walaupun mereka berbeda pendapat mengenai batas minimal dari mahar tersebut. ${ }^{9}$ Dalam pandangan mazhab Hanafi, mahar itu paling sedikitnya adalah 10 dirham. Di samping itu, bentuk mahar menurut mazhab Hanafi tidak boleh berupa pekerjaan atau manfaat. ${ }^{10}$ Sementara

\footnotetext{
${ }^{6}$ Murtadha Muthahhari, Hak-hak Wanita dalam Islam,(Jakarta: Lentera, 1995), hal. 130.

${ }^{7}$ Departemen Agama, Himpunan Peraturan Perundang-Undangan Perkawinan, (Jakarta: Direktorat JenderalBimbingan Islam, 2009), h. 240.

${ }^{8}$ Al-Ima mar-Rafi'i, Al-'Aziz Syarh al-Wajiz, (Beirut:Dar al-Kutub al-'Ilmiyyah, 2000), juz VIII: 232

${ }^{9}$ Abdul Rahman Ghozali, Fiqh Munakahat, (Jakarta: Kencana, 2014) h. 88

${ }^{10} \mathrm{Al}$-Imam al-Kasaniy, Badai' a sh-Shanai' fi Tartib a sy-Syarai', (Kairo: Dar al-Hadits, 2005), jilid III: 455; Al-Imam al-Qu duriy, Mukhtashar a l-Quduriy fiFiqh al-Imam Abi Hanifah, (Kairo: Dar al-Hadits, Vol. 5 No. 2 Oktober $2019 \quad$ Halaman $131-150$
} 
menurut mazhab Syafi'i, mahar itu tidak ada batasan minimalnya, bahkan ditegaskan bahwa apapun yang berharga atau dapat dijadikan harga bagi sesuatu atau upah boleh dijadikan mahar, yang penting dalam mahar itu adalah kerelaan istri. ${ }^{11}$

\section{METODOLOGI PENELITIAN}

Penelitian ini adalah: 1. Jenis Penelitian Penelitian ini termasuk penelitian kepustakaan (library research) yaitu penelitian yang kajiannya dilakukan dengan menelusuri dan menela'ah literatur atau penelitian yang difokuskan pada bahan-bahan pustaka. 2. Sifat Penelitian Penelitian ini bersifat deskriptif-komparatif yaitu pemaparan apa adanya terhadap apa yang dimaksud oleh suatu teks dengan cara memparafrasekan dengan bahasa penyusun, sehingga dari penelitian tersebut dapat menggambarkan secara sistematis, faktual dan akurat mengenai fakta-fakta dan sifatsifat dari obyek kajian tersebut. Di samping itu, penelitian ini juga bersif at komparatif, ${ }^{12}$ yakni membandingkan pendapat Mazhab Hanafi dan Mazhab Syafi'i tentang batas minimal mahar. 3. Teknik Pengumpulan Data Sesuai dengan jenis penelitian ini, maka pengumpulan datanya dilakukan dengan metode dokumentasi. Data primer yang digunakan dalam skripsi ini adalah kitab Al-Umm dan Badai' ash-Shanai', sementara data sekundernya adalah kitab Sunan ad-Daraquthniy dan Tahdzib at-Tahdzib. 4. Analisis Data Dalam analisis data, penyusun menganalisa data secara kualitatif dengan metode deduktif dan komparatif. Deduktif adalah metode analisis data dengan menguraikan pernyataan yang bersifat umum kemudian ditarik kesimpulan yang bersifat khusus. Sedangkan metode komparatif yaitu metode menganalisis data yang diperoleh dari fiqh Munakahat Mazhab Hanafi dan Mazhab Syafi'i tentang batas minimal mahar, kemudian membandingkan di antara keduanya agar memiliki kesimpulan yang akurat. 5. Metode Pendekatan Pendekatan yang digunakan dalam penelitian ini adalah pendekatan normatif-yuridis. Penelitian normatif-yuridis adalah penelitian yang mencakup tentang azas-azas hukum, sistematika hukum, sejarah hukum, perbandingan hukum dan taraf sinkronisasi hukum. Maka dalam penelitian ini

2017), h. 168; Mahmud Yunus, Hukum Perkawinan da lam Islam menurut Ma zhab Syafi'i, Hanafi, Maliki dan Hanbali, (Jakarta: PT. Hidakarya Agung, 1981), h. 82; Al-Imam Yahya al-'Umraniy, AlBayan fi Fiqh al-Imam asy-Syafi'i, (Beirut: Dar al-Kutub Al-'Ilmiyyah, 2002), juz IX: 333.

${ }^{11}$ Al-Ima m Yahya al- 'Umraniy, Al-Bayanfi Fiqh al-Imam asy-Syafi’i, juz IX: 332.

1226 Soerjono Soekanto, Pengantar Penelitian Hukum, (Jakarta: UI Press, 1986), h. 9-10. 
penyusun mencoba memahami konsep mahar dan batas minimalnya dengan menitikberatkan pembahasan dan kajiannya pada dasar hukum dan argumentasi Mazhab Hanafi dan Mazhab Syafi'i tentang batas minimal mahar.

\section{KAJIAN TEORI}

Kata "Mahar" berasal dari bahasa Arab dan telah diserap menjadi bahasa Indonesia. Mahar secara etimologi artinya maskawin. Mahar dalam literatur kitab-kitab fiqh juga disebut dengan beberapa nama yaitu shadaq, nihlah, faridhah, ajr, mahr, 'aliqah dan 'uqar'3. Kamus Besar Bahasa Indonesia sebagaimana yang dikutip oleh Amir Syarifuddin mendefinisikan mahar dengan "pemberian wajib berupa uang atau barang dari mempelai laki-laki kepada mempelai perempuan ketika dilangsungkan akad nikah." Definisi ini kelihatannya sesuai dengan tradisi yang berlaku di Indonesia bahwa mahar itu diserahkan ketika berlangsungnya akad nikah ${ }^{14}$.

Adapun mahar secara terminologis seperti yang dikutip Amir Syarifuddin dari ulama Mazhab Hanafi Ibnu al-Humam adalah harta yang diwajibkan atas suami ketika berlangsungnya akad nikah sebagai imbalan dari kenikmatan seksual y ang diterimanya. Sementara menurut ulama mazhab Syafi'i Taqiyyuddinal-Hushniy, mahar adalah nama bagi harta yang wajib diberikan seorang pria kepada wanita dengan sebab pernikahan atau hubungan seksual ${ }^{15}$.

Kompilasi Hukum Islam pasal 1 huruf (d) mendefinisikan mahar sebagai pemberian dari calon mempelai pria kepada calon mempelai wanita baik berbentuk barang, uang atau jasa yang tidak bertentangan dengan hukum Islam ${ }^{16}$. Dari beberapa definisi mahar di atas, bahwa mahar adalah pemberian wajib berupa uang atau barang dari seorang pria kepada wanita dengan sebab pernikahan atau hubungan seksual sebagai lambang kesungguhan dan tanggungjawab.

Para fuqaha' sepakat bahwa memberi mahar hukumnya wajib dan tidak boleh diadakan kesepakatan untuk meniadakannya ${ }^{17}$. Hal ini berdasarkan firman Allah dalam surat An-Nisa' ayat 4; surat An-Nisa' ayat 24; beberapa hadits yang menjelaskan kewajiban memberi mahar, di antaranya hadits yang berasal dari Sahl bin Sa'd riwayat

\footnotetext{
${ }^{13}$ Taqiyyuddin Al-Hushniy, Kifayah al-Akhyar, (Jakarta: Daral-Kutubal-'Ilmiyyah, 2004), juzII: 57.

${ }^{14}$ Amir Syarifudin, Hukum Perkawinan Islam di Indonesia,(Jakarta: Kencana, 2014), h. 84.

${ }^{15}$ Taqiyyuddin Al-Hushniy, Kifayahal-Akhyar, juz II: 57.

${ }^{16}$ Departemen Agama, Himpunan Peraturan Perundang-Undangan Perkawinan, (Jakarta: Direktorat Jenderal Bimbingan Islam, 2009), h. 233.

${ }^{17}$ Ibn Rusyd, Bidayahal-Mujtahid, (Indonesia: Dar Ihya al-Kutub al-'Arabiyah, t.t), juz II: 14.

Vol. 5 No. 2 Oktober $2019 \quad$ Halaman $131-150$
} 
Batas Minimal Mahar (Kajian Komparasi Antara Pendapat Mazhab Hanafi Dan Mazhab Syafi' $i)$

Imam Bukhari: Telah menceritakan kepada kami 'Abdullah bin Yusuf, telah mengabarkan kepada kami Malik, dari Abi Hazim dari Sahl bin Sa'd, Rasulullah bersabda, 'Carilah mahar meskipun cincin dari besi.' (HR. Al-Bukhari) ${ }^{18}$. Dari Ibnu Abbas, beliau berkata tatkala Ali mengawini Fatimah, maka Rasul bersabda kepadanya,"Berilah Fatimah sesuatu." Ali menjawab, "Saya tidak mempunyai sesuatu." Lalu Nabi bertanya, "Mana baju besi Huthamiyahmu?" (HR. Abu Daud, An-Nasa'i dan Ibnu Majah, dan dinilai shahih oleh Al-Hakim) ${ }^{19}$.

Dari segi dijelaskan atau tidaknya mahar itu pada waktu akad nikah, mahar itu ada 2 macam yaitu mahar musamma dan mahar mitsil (sepadan).

\section{Mahar musamma}

Mahar musamma adalah mahar yang disebutkan bentuk, wujud atau nilainya secara jelas dalam akad. Inilah mahar yang umum berlaku dalam suatu perkawinan, dan hal inilah yang disunnahkan dalam akad nikah karena Rasulullah tidak pernah melakukan akad nikah kecuali dengan mahar musamma dan agar terhindar dari perselisihan di kemudian hari ${ }^{20}$. Selanjutnya merupakan kewajiban suami untuk membayar mahar musamma selama hidupny a atau selamaberlangsungnya perkawinan. Suami wajib membayar mahar tersebut yang wujud atau nilainya sesuai dengan apa yang disebutkan dalam akad nikah itu.

\section{Mahar Mitsl}

Bila mahar tidak disebutkan jenis dan jumlahnya pada waktu akad, maka kewajibannya adalah membayar mahar sebesar mahar yang akan diterima oleh perempuan lain dalam keluarganya. Mahar dalam bentuk ini disebut mahar mitsl. Ulama Hanafiyah secara spesifik memberi batasan mahar mitsl itu dengan mahar yang pernah diterima oleh saudarinya, bibinya dan anak saudara pamannya yang sama dan sepadan umurnya, kecantikannya, kekayaannya, tingkat kecerdasannya, tingkat keberagamaannya, negeri tempat tinggalnya dan masanya dengan calon istri yang akan menerima mahar tersebut ${ }^{21}$. Senada dengan pendapat di atas, ulama Syafi'iyah juga berpendapat mahar mitsl adalah mahar yang pernah diterima saudari kandungnya lalu saudari sebapak lalu anak perempuan dari saudara kandung (keponakan sekandung)

\footnotetext{
${ }^{18}$ Al-Imam Al-Bukhariy, Shahihal-Bukhariy, (Kairo: Dar al-Hadits, t.t), jilid III: 24.

${ }^{19}$ M. Muhajirin, Mishbah azh-Zhulam, (Jakarta: Dar al-Hadits, 2014), jilid III: 212.

${ }^{20}$ Taqiyyuddin Al-Hushniy, Kifayahal-Akhyar, juz II: 58.

${ }^{21} 15$ Amir Syarifudin, Hukum Perkawinan Islam di Indonesia, h. 89.

Vol. 5 No. 2 Oktober $2019 \quad$ Halaman $131-150$
} 
lalu anak perempuan dari saudara sebapak (keponakan sebapak) lalu bibi (baik yang sekandung maupun sebapak) kemudian anak perempuan paman ${ }^{22}$.

Mengenai besarnya mahar, para fuqaha' sepakat bahwa tidak ada batas maksimal mahar. Sedangkan tentang batas minimal mahar, mereka berbeda pendapat dalam dua kelompok:

1. Ulama Hanafiyah menetapkan batas minimal mahar sebanyak 10 (sepuluh) dirham perak dan bila kurang dari itu tidak memadai dan wajib digenapkan hingga bernilai 10 dirham, dengan pertimbangan bahwa itu adalah batas minimal barang curian yang mewajibkan hadd terhadap pencurinya. Sedangkan ulama Malikiyah berpendapat bahwa batas minimal mahar adalah 3 dirham perak. Dalil bagi mereka juga adalah bandingan dari batas minimal harta yang dicuri yang mewajibkan hadd.

2. Ulama Syafi'iyah dan Hanabilah tidak memberi batas minimal mahar dengan arti apa pun yang bernilai dapat dijadikan mahar.

\section{ANALISIS PENDAPAT MAZHAB HANAFI DAN MAZHAB SYAFI'I TENTANG BATAS MINIMAL MAHAR}

1. Validitas Hadits

Hadits 'Asyarah Darahim Untuk mengetahui sejauhmana validitas hadits yang dikemukakan oleh mazhab Hanafi, maka perlu diteliti, apakah hadits itu berkualitas shahih, hasan atau dha' if sesuai dengan kaidah-kaidah yang digariskan para ulama yaitu kaidah kesahihan hadits bila hadits yang diteliti bukan hadits mutawatir. ${ }^{23}$ Mengenai hadits 'Asyarah Darahim, penyusun menemukan ada beberapa sanad yang semuanya melewati jalur Mubasysyir bin 'Ubaid. ${ }^{24}$. Sanad yang dimaksud adalah:

“(Ad-Daraquthniy berkata) Telah menceritakan kepada kami Ahmad bin 'Isa as-Sukayn, telah menceritakan kepadakami Zakariyyabin al-Hakam ar-Ras'aniy, telah menceritakan kepada kami Abu al-Mughirah 'Abd al-Quddus bin al-Hajjaj, telah menceritakan kepada kami Mubasysyir bin 'Ubaid, ia berkata, telah menceritakan kepadaku al-Hajjaj bin Arthah dari 'Atha' dan 'Amr bin Dinar dari Jabir bin Abdillah, ia berkata, "Rasulullah shallallahu 'alayhi wasallam bersabda, 'Jangan kalian nikahkan

\footnotetext{
${ }^{22}$ Taqiyyuddin Al-Hushniy, Kifayahal-Akhyar,juz II: 60.

${ }^{23}$ Syuhudi Ismail, Metodologi Penelitian Hadis, (Jakarta: Bulan Bintang, 1992), h. 63.

${ }^{24}$ Ibrahim, "Catatan Ka ki No. 3601 ", da lam Al-Hafizh ad-Daraquthniy, Sunan ad-Daraquthniy, juz III: 189.

Vol. 5 No. 2 Oktober $2019 \quad$ Halaman $131-150$
} 
para wanita kecuali dengan calon suami yang sekufu', dan jangan menikahkan para wanita kecuali oleh walinya dan mahar tidak boleh kurang dari 10 dirham."

Setelah mendapatkan sanad hadits tersebut, maka perlu diteliti biografi para perawi untuk mengetahui apakah sanadnya muttashil atau tidak serta apakah para perawi di atastsiqah (dapat dipercaya), adil dan dhabith (kuat ingatan). Berikut pemaparan biografi mereka:

a) Imam ad-Daraquthniy (306-385 H) ; Nama lengkapnya: Abu al-Hasan 'Ali bin 'Umar bin Ahmad bin Mahdiyal-Baghdadiy ad-Daraquthniy. Guru dan muridnya di bidang periwayatan hadits: Guru imam ad-Daraquthniy banyak sekali, antara lain Abu al-Qasim al-Baghawiy dan lain-lain. Murid beliau juga banyak antara lain, Muhammad bin al-Hasan asy-Syaibaniy dan lain-lain. Penyataan kritikus hadits tentang dirinya: 1) Ibnu al-Jawziy: Beliau adalah orang yang paling hafal hadits di masanya dan paling mengetahui riwayatriwayat hadits. 2) Ibnu Katsir: Sejak kecil, beliau terkenal sebagai orang yang mempunyai hafalan yang melimpah dan pemahaman yang mendalam.3) AlKhathib al-Baghdadiy: Saya mendengar Abu ath-Thayyib ath-Thabariy berkata, 'Ad-Daraquthniy adalah amir al-Mu'minin fil-hadits. ${ }^{25}$

Tidak ada satu kritikus hadits pun yang mencela Ad-Daraquthniy. Pujian yang diberikan orang kepadanya adalah pujian yang berperingkat tinggi dan tertinggi, bahkan disebut sebagai amir al-Mu'minin fil-hadits; gelar tertinggi dalam ilmu hadits seperti layaknya Imam Bukhariy. Dengan demikian, pernyataannya yang mengatakan bahwa dia telah menerima hadits di atas dari Ahmad bin 'Isa dapat dipercaya. Hal ini berarti antara beliau dengan Ahmad bin 'Isa bersambung sanadnya.

b) Ahmad bin 'Isa bin as-Sukain al-Baladiy. Nama lengkapnya: Ahmad bin 'Isa bin as-Sukain bin 'Isa bin Fairuz, Abu al-'Abbas asy-Syaibaniy al-Baladiy alMawshiliy. Guru dan muridnya di bidang periwayatan hadits: Guru Ahmad bin 'Isa cukup banyak, antara lain Ahmad bin Zuhair bin Abi Khaitsamah, Zakariyya bin al-Hakam ar-Ras'aniy, Wahb bin Hafsh dan lain-lain. Murid beliau juga banyak antara lain, Ahmad bin Ibrahim Ath-Thabaraniy, 'Ali bin 'Umar ad-Daraquthniy dan lain-lain. Penyataan kritikus hadits tentang dirinya:

\footnotetext{
${ }^{25}$ Ibrahim, "Muqaddimah", dalam Al-Hafizh a d-Daraquthniy, Sunan ad-Daraquthniy, juz I: 6-8. 55 Vol. 5 No. 2 Oktober $2019 \quad$ Halaman $131-150$
} 
1) Al-Khathib al-Baghdadiy: Beliau orang yang tsiqah. ${ }^{26}$

Tidak ada kritikus hadits yang mencela Ahmad bin 'Isa. Pujian yang diberikan orang kepadanya adalah pujian yang tinggi. Dengan demikian, pernyataannya yang mengatakan bahwa dia telah menerima hadits di atas dari Zakariyya bin al-Hakam arRas'aniy dapat dipercaya. Hal ini berarti antara beliau dengan Zakariyya bin al-Hakam ar-Ras'aniy bersambung sanadnya.

c) Zakariyya bin al-Hakam ar-Ras'aniy. Nama lengkapnya: Zakariyya bin alHakam al-Asadiy ar-Ras'ani. Guru dan muridnya di bidang periwayatan hadits: Guru Zakariyya bin al-Hakam cukup banyak, antara lain Yazid bin Harun, Abdullah bin Bakr as-Sahmiy dan lain-lain. Murid beliau di antaranya Abu 'Arubah dan lain-lain. Penyataan kritikus hadits tentang dirinya: 1) Ibnu Hibban: Beliau termasuk orang yang tsiqah. ${ }^{27}$

d) Abu al-Mughirah Abd al-Quddus.Nama lengkapnya: Abd al-Quddus bin alHajjaj al-Khawlaniy. Guru dan muridnya di bidang periwayatan hadits: Guru Abd al-Quddus cukup banyak, antara lain Hariz bin Utsman, Shafwan bin 'Amr, al-Awza'iy dan lain-lain. Murid beliau juga banyak antara lain, Imam alBukhariy, Muhammad bin Mushaffa dan lain-lain. Penyataan kritikus hadits tentang dirinya: 1) Abu Hatim: Beliau orang yang sangat jujur. 2) Al-'Ijliy: Beliau tsiqah. 3) Ibnu Hibban: Beliau termasuk orang yang tsiqah. ${ }^{28}$

Tidak ada satu kritikus hadits pun yang mencela Abd al-Quddus, bahkan beliau disebut orang yang sangat jujur. Dengan demikian, pernyataannya yang mengatakan bahwa dia telah menerima hadits di atas dari Mubasysyir bin 'Ubaid dapat dipercaya. Hal ini berarti antara beliau dengan Mubasysyir bin 'Ubaid bersambung sanadnya.

e) Mubasysyir bin 'Ubaid. Nama lengkapnya: Mubasysyir bin 'Ubaid al-Qurasyi Abu Hafsh. Guru dan muridnya di bidang periwayatan hadits: Guru Mubasysyir bin 'Ubaid di antaranya Zaid bin Aslam, Qatadah, Az-Zuhriy dan lain-lain. Muridnya antara lain, Baqiyyah, Abu al-Mughirah dan lain-lain. Penyataan kritikus hadits tentang dirinya: 1) Ahmad bin Hanbal: Hadits-hadits Mubasysyir

\footnotetext{
${ }^{26}$ Al-Khathib al-Baghdadiy, Tarikh Baghdad, (Beirut: Daral-Fikr, t.t), juz V: 461.

${ }^{27}$ 6Ibnu Hibban, Kitabats-Tsiqat, (Beirut:Daral-Fikr, 1982), juz VIII: 255.

${ }^{28}$ Ibnu Hajar a l-‘Asqalaniy, Tahdzib at-Tahdzib, (Kairo: Dar al-Hadits, 2010), jilid IV: 470-471.

Vol. 5 No. 2 Oktober $2019 \quad$ Halaman $131-150$
} 
bin 'Ubaid palsu. 2) Al-Bukhariy: Hadits Mubasysyir bin 'Ubaid munkar. 3) Ad-Daraquthniy: Mubasysyir bin 'Ubaidmatruk al-hadit ${ }^{29}$

Para kritikus hadits mencela Mubasysyir bin 'Ubaid, bahkan Ahmad bin Hanbal menuduhnya memalsukan hadits, karena itu, pernyataannya yang mengatakan bahwa dia telah menerima hadits di atas dari Hajjaj bin Arthah tidak dapat dipercaya danhadits yang diriwayatkannya mungkin hanya bualannya saja.

f) Al-Hajjaj bin Arthah. Nama lengkapnya: Al-Hajjaj bin Arthah bin Tsawr bin Hubairah bin Syarahil bin Ka'b an-Nakha'iy al-Kufiy. Guru dan muridnya di bidang periwayatan hadits: Guru Al-Hajjaj bin Arthah antara lain Asy-Sya'biy, Atha, Amr bin Syu'aib dan lain-lain. Murid beliau juga banyak antara lain, Syu'bah, Sufyan, Ibn al-Mubarak dan lain-lain. Penyataan kritikus hadits tentang dirinya: 1) Ibnu Ma'in: Al-Hajjaj bin Arthah orang yang sangat jujur, tapi ia melakukan tadlis. 2) Abu Hatim: Al-Hajjaj bin Arthah orang yang sangat jujur, tapi ia melakukan tadlis dari orang-orang yang lemah. 3) Al-Khathib alBaghdadiy: Hajjaj bn Arthah adalah salah seorang ulama hadits. ${ }^{30}$

Al-Hajjaj bin Arthah adalah orang yang jujur, hanya saja kadang melakukan tadlis, karena itu mengingat kejujurannya dapat dikatakan bahwa ia mungkin saja menerima hadits ini dari 'Atha.

g) 'Atha bin Abi Rabah. Nama lengkapnya: 'Atha bin Abi Rabah. Guru dan muridnya di bidang periwayatan hadits: Guru beliau antara lain Aisyah, Ummu Salamah, Abu Hurayrah, Ibnu Abbas, Jabir dan lain-lain. Murid beliau juga banyak antara lain, Mujahid, 'Amr bin Dinar, Abu Hanifah, Hajjaj bin Arthah dan lain-lain. Penyataan kritikus hadits tentang dirinya: 1) Ahmad bin Hanbal: 'Atha bin Abi Rabah penduduk Mekkah, seorang Tabi'iy dan tsiqah. Beliau seorang Mufti Mekah. 2) An-Nawawiy: Para ulama sepakat bahwa 'Atha bin AbiRabah adalah orangyang tsiqah dan imam yangagung. 3) Yahya bin Ma' in: Beliau adalah orang yang tsiqah. ${ }^{31}$

\footnotetext{
${ }^{29} 8$ Al-Hafizh al-Mizziy, Tahdzibal-Kamalfi Asma' ar-Rijal, (Beirut:Daral-Fikr, 1994), juzXVII: 424 .

${ }^{30}$ Al-Khathib al-Baghdadiy, Tarikh Baghdad, juz VIII: 230-236.

${ }^{31} 10$ Abd al-Hayy al-Hanbaliy, Syadzarah adz-Dzahabfi Akhbari Man Dzahab, (Beirut: Dar al-Fikr, 1994), juz I: 147-148.

Vol. 5 No. 2 Oktober $2019 \quad$ Halaman $131-150$
} 
Tidak ada satu kritikus hadits pun yang mencela 'Atha bin Abi Rabah. Pujian yang diberikan orang kepadanya adalah pujian yang tinggi, bahkan disebut sangat menguasai ilmu fiqh. Dengan demikian, pernyataannya yang mengatakan bahwa dia telah menerima hadits dari Jabir dapat dipercaya. Hal ini berarti antara beliau dengan Jabir bersambung sanadnya.

h) 'Amr bin Dinar. Nama lengkapnya:'Amr bin Dinaral-Makkiy Abu Muhammad al-Atsram al-Jumahiy. Guru dan muridnya di bidang periwayatan hadits: Guru 'Amr bin Dinar banyak sekali, antara lain Ibnu Abbas, Ibnu Umar, Abu Hurairah, Jabirdan lain-lain. Murid beliau juga banyak antara lain Qatadah, Ayyub, Syu'bah dan lain-lain. Penyataan kritikus hadits tentang dirinya: 1) Sufyan bin 'Uyainah: 'Amr bin Dinar tsiqah, teliti, banyak haditsnya, sangat jujur dan 'alim. 2) Abu Zur'ah: 'Amr bin Dinar orang yang tsiqah. 3) Abu Hatim:"Amr bin Dinar tsiqah. ${ }^{32}$

Tidak ada satu kritikus hadits pun yang mencela 'Amr bin Dinar. Pujian yang diberikan orang kepadanya adalah pujian yang tinggi, bahkan disebut sangat jujur dan 'alim. Dengan demikian, pernyataannya yang mengatakan bahwa dia telah menerima hadits dari Jabir dapat dipercaya. Hal ini berarti antara beliau dengan Jabir bersambung sanadnya.

i) Jabir. Nama lengkapnya: Jabir bin Abdillah bin Amr bin Haram bin Tsa'labah. Guru dan muridnya di bidang periwayatan hadits: Shahabat Jabir menerima hadits langsung dari Nabi dan juga para shahabat senior seperti Abu Bakar, Umar, Ali dan lain-lain. Murid beliau jugabanyak antara lain Sa'id bin alMusayyab, al-Hasan al-Bashriy, Atha' bin Abi Rabah, dan lain-lain. ${ }^{33} J a b i r$ termasuk shahabat Nabi. Para shahabat tidak mungkin berdusta berkaitan dengan kabar y ang datang dari Nabi, dan semua ulama juga sepakat bahwa para shahabat semuanya adalah orang yang jujur dan adil.

Berdasarkan penelusuran biografi para perawi hadits ini, nampak bahwa semua perawinya adalah orang yang tsiqah dan ucapannya dapat dipertanggungjawabkan kecuali Mubasysyir bin 'Ubaid. Ia dituduh memalsukan hadits oleh Ahmad bin Hanbal sehingga hadits ini termasuk hadits matruk yang merupakan hadits dha'if yang tidak

\footnotetext{
${ }^{32}$ Ibnu Hajar al-'Asqalaniy, Tahdzib at-Tahdzib, (Kairo: Dar al-Hadits, 2010), jilid V: 367-369. 60

${ }^{33}$ Ibnu Hajar al-'Asqalaniy, Tahdzib at-Tahdzib, (Kairo: Dar al-Hadits, 2010), jilid I: 549-550.

Vol. 5 No. 2 Oktober $2019 \quad$ Halaman $131-150$
} 
dapat dijadikan hujjah dalam bidang fiqh. Hadits matruk adalah hadits yang pada sanadnya terdapat rawi yang tertuduh berdusta dan hanya dia seorang yang meriwayatkan dari thabaqah di atasnya.

\section{Hadits Iltamis}

Sama dengan penelitian di atas, berkaitan hadits Itamis, penyusun menemukan hadits ini mempunyai beberapa sanad yang ditakhrij oleh Imam Bukhariy, Imam Muslim, Imam Malik, Imam Abu Dawud, Imam Tirmidzi dan Imam Syafi'i. ${ }^{34}$ Dalam skripsi ini hanya akan diteliti satu sanad saja menurut riwayat Imam Syafi'i seperti yang termaktub dalam kitab beliau al-Umm. Sanad yang dimaksud adalah:

“(Imam Syafi’i berkata) Telah mengabarkan kepada kami Imam Malik dari Abi Hazim dari Sahl bin Sa'd, (ia berkata) "Seorang wanita datang kepada Nabi shallallahu 'alayhi wasallam lalu ia berkata, 'Sungguh aku serahkan diriku kepadamu'. Kemudian dia berdiri dalam waktu yang lama. Lalu ada seorang pria berdiri dan berkata, 'Nikahkanlah dia kepadaku apabila engkau tidak berminat.' Lalu Rasulullah bersabda, 'Apakah kamu mempunyai sesuatu untuk dijadikan maharnya?' Pria itu menjawab, 'Saya tidak mempunyai apa-apa kecuali sarungku ini.' Nabi bersabda, 'Jika kamu berikan sarung itu kepadanya, maka kamu akan duduk tanpa bersarung, karena itu, carilah sesuatu'. Lalu pria itu berkata, 'Saya tidak mendapati apapun.' Lalu Rasulullah bersabda, 'Carilah (mahar) meskipun cincin dari besi.' Kemudian pria itu mencari dan ia tidak mendapati apapun. Maka pria itu berkata, 'Saya tidak menemukan apapun.' Lalu Rasulullah bersabda, 'Apakah kamu hafal beberapa surat Al-Qur'an?' Ia menjawab, 'Ya, surat ini dan surat ini', ada beberapa surat yang ia sebutkan. Maka Rasulullah shallallahu 'alayhi wasallam bersabda, 'Sungguh Aku nikahkan engkau dengan wanita itu dengan (mahar) mengajarkan beberapa surat Al-Qur'an yang kau hafal.' 35

Setelah mendapatkan sanad hadits tersebut, maka perlu diteliti biografi para perawi untuk mengetahui apakah sanadnya muttashil atau tidak serta apakah para perawi di atas adil dan dhabith. Berikut pemaparan biografi mereka:

\footnotetext{
${ }^{34}$ M. Ibrahim al-Hifnawiy, "Catatan Kaki No. 3" da lam Imam Syafi' i, al-Umm, (Kairo: Dar al-Hadits, 2008),juz VI: 141

${ }^{35}$ Imam Syafi'i, al-Umm, (Ka iro: Daral-Hadits, 2008), juz VI: 140-141. 62

Vol. 5 No. 2 Oktober 2019

Halaman 131 - 150
} 
a) Imam Syafi'i.Nama lengkapnya: Abu 'Abdillah Muhammad bin Idris bin al'Abbas bin Utsman bin Syafi' bin as-Saib bin 'Ubaid bin Abdi Yazid bin Hasyim bin Muththalib bin Abdi Manaf. Guru dan muridnya di bidang periwayatan hadits: Guru Imam Syafi'i cukup banyak, antara lain Muslim bin Khalid az-Zanjiy, Malik bin Anas, Ibrahim bin Sa'd dan lain-lain. Murid beliau juga banyak antara lain, Ahmad bin Hanbal, Harmalah, Al-Buwaithi dan lainlain.Penyataan kritikus hadits tentang dirinya: 1) Abu Zur'ah ar-Raziy: Syafi'i tidak pernah meriwayatkan satu hadits pun yang salah. 2) Abu Hatim: Beliau adalah orang yang faqih dan sangat jujur. 3) An-Nasai: Beliau adalah salah seorang ulama kita yang tsiqah dan dapat dipercaya. ${ }^{36}$

Tidak ada satu kritikus hadits pun yang mencela Imam Syafi'i. Pujian yang diberikan orang kepadanya adalah pujian yang berperingkat tinggi dan tertinggi. Dengan demikian, pernyataannya yang mengatakan bahwa dia telah menerima hadits di atas dari Malik bin Anas dapat dipercaya. Hal ini berarti antara beliau dengan Imam Malik bin Anas bersambung sanadnya.

b) Malik.Nama lengkapnya: Malik bin Anas bin Malik bin Abi 'Amir bin 'Amr; Imam Dar al-Hijrah. Guru dan muridnya di bidang periwayatan hadits: Guru Imam Malik bin Anas cukup banyak, antara lain 'Amir bin Abdullah, Zaidbin Aslam, Abi Hazim Salamah bin Dinar, dan lain-lain. Murid beliau juga banyak antara lain, Az-Zuhriy, Yahya bin Sa'id al-Anshariy, Syafi'idan lain-lain. Penyataan kritikus hadits tentang dirinya: 1) Yahya bin Ma'in: Malik bin Anas orang yang tsiqah. 2) An-Nasai: Di kalangan Tabi'in tidak ada orang yang lebih cerdas, lebih agung, lebih dapat dipercaya daripada Malik. 3) Ibnu Hibban: Beliau adalah orang pertama yang menyelidiki ihwal keadaan para perawi dari kalangan fuqaha ' Madinah, dan beliau berpaling dari perawi yang tidak tsiqah. Beliau tidak meriwayatkan kecuali hadits yang shahih dan hanya meriwayatkan dari orang yang tsiqah. ${ }^{37}$

Tidak ada satu kritikus hadits pun yang mencela Imam Malik bin Anas. Pujian yang diberikan orang kepadanya adalah pujian yang berperingkat tinggi dan tertinggi. Dengan demikian, pernyataannya yang mengatakan bahwa beliau telah menerima

\footnotetext{
${ }^{36}$ Ibnu Hajar al-'Asqalaniy, Tahdzibat-Tahdzib, (Kairo: Dar al-Hadits, 2010), jilid VI: 121-126.

${ }^{37}$ Ibid.,jilid VI: 571-575. 
hadits di atas dari Abu Hazim dapat dipercaya. Hal ini berarti antara beliau dengan Abu Hazim bersambung sanadnya.

c) Abu Hazim.Nama lengkapnya: Salamah bin Dinar Abu Hazim al-A'raj alMadaniy. Guru dan muridnya di bidang periwayatan hadits: Guru Abu Hazim cukup banyak, antara lain Sahl bin Sa'd, Abu Umamah, Sa'id bin al- Musayyab dan lain-lain. Murid beliau juga banyak antara lain, Az-Zuhriy, Ibnu Ishaq, Ibnu Abi Dzi'b dan lain-lain. Penyataan kritikus hadits tentang dirinya: 1) Ibnu Hajar al-'Asqalaniy: Abu Hazim tsiqah dan menjabat qadhi di Madinah, beliau rajn beribadah dan zuhud. 2) Abu Hatim: Beliau adalah orang yang tsiqah.3) AnNasa'i: Beliau tsiqah. ${ }^{38}$

Tidak ada satu kritikus hadits pun yang mencela Abu Hazim. Pujian yang diberikan orang kepadanya adalah pujian yang tinggi. Dengan demikian, pernyataannya yang mengatakan bahwa beliau telah menerima hadits di atas dari Sahl bin Sa'd dapat dipercaya. Hal ini berarti antara beliau dengan Sahl bin Sa'd bersambung sanadnya.

d) Sahl bin Sa'd. Nama lengkapnya: Sahl bin Sa'dbin Malik bin Khalid bin Tsa'labah al-Anshariy as-Sa'idiy. Guru dan muridnya di bidang periwayatan hadits: Sahl bin Sa'dmeriwayatkan hadits langsung dari Nabi, Ubay bin Ka’b, 'Ashi bin 'Adiy dan lain-lain. Murid beliau juga banyak antara lain, Az-Zuhriy, Abu Hazim, Yahya bin Maymun dan lain-lain. ${ }^{39}$ Sahl bin Sa'd merupakan shahabat Nabi. Para shahabat tidak mungkin berdusta berkaitan dengan kabar yang datang dari Nabi, dan semua ulama juga sepakat bahwa para shahabat semuanya adalah orang yang jujur dan adil.

Dari penelitian tentang kepribadian para perawi di atas, nampak bahwa semua rawi yang meriwayatkan hadits di atas tsiqah dan sanadnya muttashil. Selain itu, hadits ini tidak bertentangan dengan hadits lain yang diriwayatkan oleh orang yang lebih tsiqah (tidak syadz) dan tidak mengandung 'illat. Dengan demikian, hadits ini berkualitas shahih.

\section{Qiyas}

Qiyas adalah menyamakan hukum sesuatu yang tidak disebutkan dalam AlQur'an dan As-Sunnah dengan sesuatu yang hukumnya telah disebutkan dalam Al-

\footnotetext{
${ }^{38}$ Ibid., jilid III: 149-150.

${ }^{39}$ Ibid., jilid III: 244-245

Vol. 5 No. 2 Oktober 2019

Halaman $131-150$
} 
Qur'an dan As-Sunnah karena adanya kesamaan 'illah. Mazhab Hanafi mengqiyaskan batas minimal mahar dengan batas minimal harta curian yang men yebabkan hukuman potong tangan. Sesungguhnya apabila dicermati, tentu qiyas ini kurang tepat dengan beberapa alasan:

1) Mahar diberikan agar hubungan badan (senggama) antara pria dan wanita yang tadinya haram menjadi halal, sementara hukuman potong tangan ditegakkan karena tindakan pencurian yang jelas-jelas haram, dan tidak akan berubah menjadi halal.

2) Mahar diberikan agar suami dapat berhubungan badan dengan halal (istibahah ' $u d h w$ ) dan anggota badan istri yang berkaitan dengan senggama tidak dilukai; tetap utuh. Sementara hukuman pencurian bila barang yang dicuri telah sampai nishab, maka tangan si pencuri akan dilukai; dipotong dan tidak utuh lagi.

3) Menurut sebagian ulama, mahar adalah imbal balik senggama yang dilakukan oleh suami. Pihak suami memberikan mahar, dan pihak istri memperbolehkan suami berhubungan badan dengan dirinya. Sementara dalam hukuman potong tangan tidak ada pertukaran antara pencuri dan orang yang hartanya dicuri. Sedangkan menurut sebagian ulama yang lain, mahar bukanlah imbal balik senggama, melainkan kewajiban yang dibebankan oleh Allah kepada suami.

4) Mahar diberikan dalam suasana kegembiraan, sedangkan hukuman potong tangan tentu dalam suasana sedih dan jauh dari kegembiraan.

\section{PANGKAL PERBEDAAN PENDAPAT ANTARA MAZHAB HANAFI DAN MAZHAB SYAFI'I}

Pangkalperbedaan pendapat antara mazhab Hanafi dan mazhab Syafi'i tentang batas minimal mahar adalah:

1) Dalil yang mereka gunakan sebagai hujjah berbeda. Mazhab Hanafi menggunakan hadits 'Asyarah Darahim dan qiyas. Sedangkan mazhab Syafi'i menggunakan hadits Iltamis. Di muka, telah dijelaskan berdasarkan penelitian perawi hadits, sesungguhnya hadits yang dijadikan dalil oleh mazhab Hanafi adalah hadits yang dha'ifsehingga tidak dapat dijadikan hujjah. Sementara hadits yang dijadikan dalil oleh mazhab Syafi'i adalah hadits yang shahih. Tentu, hadits yang shahih didahulukan dan dijadikan pegangan dalam masalah hukum. Dalam padaitu, ulama mazhab Hanafi juga mengakui keshahihan hadits Sahl, tetapi mereka mengartikan bahwa Nabi memerintahkan kepada pemuda 
yang tidak memiliki harta itu untuk memberikan mahar yang disegerakan; mahar pendahuluan meskipun kecil 68 nilainya seperti cincin dari besi dan di kemudian hari tetap harus memberikan batas minimal mahar yaitu sepuluh dirham.

2) Metodologi istinbath hukum keduanya juga berbeda. Mazhab Hanafi lebih mendahulukan qiyas yang digali nash-nash agama (Al-Qur'an dan Hadits Mutawatir) dari pada menggunakan hadits Ahad yang shahih. Hadits Iltamis adalah hadits Ahad yang shahih yang tidak mencapai derajat mutawatir. Karena hadits ini tidak mutawatir, ulama mazhab Hanafi tidak menjadikah hadits ini sebagai pegangan pokok dalam masalah mahar, justru mereka menggunakan qiyas karena menyamakan mahar dengan batas minimal anggota tubuh yang dihalalkan untuk diqishash. Qiyas dalam masalah ini digali dari Al-Qur'an Surat An-Nisa: 24 yang berbunyi, "Wa Uhilla Lakum Ma Wara'a Dzalikum An Tabtaghu bi Amwalikum. "Dari ayat ini, ulama mazhab Hanafi memahami bahwa kehalalan menikahi perempuan-perempuan yang bukan mahram dan semacamnya itu dengan kadar harta tertentu, bukan dengan sembarang harta. Karena apabila kehalalan menikah itu dengan sembarang harta; kadar harta yang terlalu rendah, maka ini tidak mencerminkan pentingnya senggama, dan telah diketahui secara syara' bahwa kadar anggota tubuh yang penting yang dapat dihalalkan adalah sepuluh dirham, maka untuk kehalalan menikah juga ditentukan dengan sepuluh dirham.

3) Di lain sisi, mazhab Syafi'i memandang hadits Ahad yang shahih meskipun tidak mutawatir dapat dan harus dijadikan pegangan hukum. Bahkan ada diktum yang terkenal dalam mazhab Syafi'i, "Qiyas tidak berlaku apabila ada nash." Dengan metodologi ini, ulama mazhab Syafi'i lebih mendahulukan hadits yang shahih meskipun tidak mutawatir. Karena Nabi bersabda, "Carilah mahar meskipun berupa cincin dari besi”, maka dapat disimpulkan mahar boleh berupa apa saja yang pentinga ada nilainya meskipun kecil. Terbukti dari sabda Nabi yang memerintahkan pemuda itu untuk mencari cincin dari besi, dan tentu kita semua tahu harga cincin dari besi sangat murah dan tidak mungkin mencapai sepuluh dirham. Di samping itu, sabda Nabi ini dalam nuansa mencari yang paling sedikit. Seandainya maksud Nabi dalam sabdanya ini adalah mahar yang 
disegerakan, tentu Nabi tinggal bersabda, "Carilah mahar sepuluh dirham", dan ini lebih mudah dan lebih mudah dipahami. Akan tetapi, kenyataannya Nabi tidak bersabda demikian.

4) Perbedaan pendapat antar para ulama adalah rahmat. Meskipun ulama mazhab Syaf'i berpendapat batas minimal mahar dapat berupa apa saja; segala sesuatu yang bernilai meskipun kecil, tetapi mereka juga berpendapat disunnahkan bagi pengantin pria untuk memberikan mahar sebesar sepuluh dirham kepada pengantin wanita. Karena mereka berpendapat 'Keluar dari perbedaan pendapat ulama disunnahkan'. Dari sini bisa dilihat bahwa para ulama saling menghargai pendapat lain yang bertolak belakang dengan pendapatnya dan sedapat mungkin mengambil pendapat tersebut sepanjang masih dalam koridor yang diperkenankan oleh agama. Sebab semua pendapat ulama adalah hasil ijtihad yang digali setelah mengkaji ayat-ayat suci Al-Qur'an, As-Sunnah, Ijma' dan Qiyas. Hasil ijthad tidak keluar dari sembarang orang, melainkan diproduksi oleh mujtahid, dan Nabi telah menjanjikan apabila seorang mujtahid menggali hukum dan produk hukumnya itu benar dan tepat maka ia akan mendapat dua pahala, sementara mujtahid yang produk hukumnya salah; tidak tepat, maka ia tetap akan mendapat satu pahala.

\section{KESIMPULAN}

Dari penelitian pustaka yang penulis lakukan, dapat disimpulkan bahwa: Batas minimal mahar menurut mazhab Hanafi adalah 10 (sepuluh) dirham dan tidak boleh kurang dari nominal tersebut. Dasar hukum dan argumentasi mereka dalam hal ini adalah hadits riwayat Imam Ad-Daraquthniy di mana Nabi bersabda, "Wa La Mahra Duna Asyarah Darahim." (Mahar tidak boleh kurang dari 10 dirham). Hadits ini setelah dilakukan penelitian sederhana adalah hadits matruk yang termasuk hadits dha'if. Di samping itu, mereka juga berargumen dengan qiyas. Mereka mengqiyaskan batas minimal mahar dengan batas minimal harta curian yang menyebabkan hukuman potong tangan yaitu 10 dirham. Qiyas ini digali dari Surat An-Nisa: 24 yang berbunyi, "Wa Uhilla Lakum Ma Wara'a Dzalikum An Tabtaghu bi Amwalikum.” Menurut mazhab Syafi'i, mahar itu tidak ada batas minimalnya, bahkan ditegaskan bahwa apapun yang berharga atau dapat dijadikan harga bagi sesuatu atau upah boleh dijadikan mahar, yang penting dalam mahar itu adalah kerelaan istri. Dasar hukum dan argumentasi mereka 
dalam hal ini adalah hadits riwayat Imam Malik, Imam Syafi'i, Imam Bukhariy, Imam Muslim, Imam Abu Dawud dan Imam Tirmidzi di mana Nabi bersabda, "Iltamis Walaw Khataman min Hadidin." (Carilah mahar meskipun cincin dari besi). Hadits ini setelah dilakukan penelitian sederhana adalah hadits shahih yang dapat dijadikan pegangan hukum. Selain hadits ini, mereka juga berargumen dengan surat An-Nisa': 4 yang berbunyi, "Wa Uhilla Lakum Ma Wara'a Dzalikum An Tabtaghu bi Amwalikum." Perbedaan pandangan tentang batas minimal mahar antara mazhab Hanafi dan mazhab Syafi'i berpangkal dari perbedaan hadits yang dijadikan dalil. Mazhab Hanafi menggunakan hadits "Wa La Mahra Duna Asyarah Darahim.” Sementara mazhab Syafi'i menggunakan hadits "Iltamis Walaw Khataman min Hadidin." Selain itu, produk hukum yang berbeda antara kedua mazhab ini juga lahir dari perbedaan metode istinbath mereka.

\section{DAFTAR PUSTAKA (BIBLIOGRAPHY)}

Abd al-Hayy al-Hanbaliy, Syadzarahadz-DzahabfiAkhbariMan Dzahab, (Beirut: Dar al-Fikr, 1994), juz I: 147-148.

Abdul Rahman Ghozali, Fiqh Munakahat, (Jakarta: Kencana, 2014) h. 88

Ahmad Azhar Basyir, Hukum Perkawinan Islam, (Yogyakarta: UII Press, 1999), h 1.

Ahmad Azhar Basyir, Hukum Perkawinan Islam, h. 54.

Al-Hafizh ad-Daraquthniy, Sunan ad-Daraquthniy, (Kairo: Dar al-Hadits, 2014), juz III: 189.53

Al-Hafizh al-Mizziy, Tahdzib al-Kamal fi Asma' ar-Rijal, (Beirut: Dar al-Fikr, 1994), juz XVII: 424.

Al-Imam al-Kasaniy, Badai' ash-Shanai’ fi Tartib asy-Syarai', (Kairo: Dar al-Hadits, 2005), jilid III: 455; Al-Imam al-Quduriy, Mukhtashar al-Quduriy fi Fiqh alImam Abi Hanifah, (Kairo: Dar al-Hadits, 2017), h. 168; Mahmud Yunus, Hukum Perkawinan dalam Islam menurut Mazhab Syafi'i, Hanafi, Maliki dan Hanbali, (Jakarta: PT. Hidakarya Agung, 1981), h. 82; Al-Imam Yahya al'Umraniy, Al-Bayan fi Fiqh al-Imam asy-Syafi'i, (Beirut: Dar al-Kutub Al'Ilmiyyah, 2002), juz IX: 333.

Al-Imam ar-Rafi'i, Al-‘Aziz Syarh al-Wajiz, (Beirut: Dar al-Kutub al-'Ilmiyyah, 2000), juz VIII: 232 
Batas Minimal Mahar (Kajian Komparasi Antara Pendapat Mazhab Hanafi Dan Mazhab Syafi'i)

Al-Imam Yahya al-'Umraniy, Al-Bayan fi Fiqh al-Imam asy-Syafi'i, juz IX: 332.

Al-Khathib al-Baghdadiy, Tarikh Baghdad, (Beirut: Dar al-Fikr, t.t), juz V: 461.

Al-Khathib al-Baghdadiy, Tarikh Baghdad, juz VIII: 230-236.

Anton Bakker, Metode-metode Filsafat, (Jakarta: Ghalia Indonesia, 1986), h. 6.

Departemen Agama, Himpunan Peraturan Perundang-Undangan Perkawinan, (Jakarta: Direktorat Jenderal Bimbingan Islam, 2009), h. 240.

Firdaweri, Hukum Islam tentang Fasakh Perkawinan Karena Ketidakmampuan Suami Menunaikan Kewajibannya, (Jakarta: CV Pedoman Ilmu Jaya, 1989), h. 14.

Ibnu Hajar al-'Asqalaniy, Tahdzib at-Tahdzib, (Kairo: Dar al-Hadits, 2010), jilid IV: 470-471.

Ibnu Hajar al-'Asqalaniy, Tahdzib at-Tahdzib, (Kairo: Dar al-Hadits, 2010), jilid V: 367-369. 60

Ibnu Hajar al-‘Asqalaniy, Tahdzibat-Tahdzib, (Kairo:Dar al-Hadits, 2010), jilid I:549550 .

Ibnu Hajar al-'Asqalaniy, Tahdzib at-Tahdzib, (Kairo: Dar al-Hadits, 2010), jilid VI: 121-126.

Ibnu Hibban, Kitab ats-Tsiqat, (Beirut: Dar al-Fikr, 1982), juz VIII: 255.

Ibrahim, "Catatan Kaki No. 3601”, dalam Al-Hafizh ad-Daraquthniy, Sunan adDaraquthniy, juz III: 189.

Ibrahim, "Muqaddimah", dalam Al-Hafizh ad-Daraquthniy, Sunan ad-Daraquthniy, juz I: 6-8. 55

Imam Syafi'i, al-Umm, (Kairo: Dar al-Hadits, 2008), juz VI: 140-141. 62

Khoiruddin Nasution, Hukum Perkawinan I, (Yogyakarta: Academia+Tazzafa, 2013), h. 179.

M. Ibrahim al-Hifnawiy, “Catatan Kaki No. 3” dalam Imam Syafi'i, al-Umm, (Kairo: Dar al-Hadits, 2008), juz VI: 141

Murtadha Muthahhari, Hak-hak Wanita dalam Islam, (Jakarta:Lentera, 1995), hal. 130.

Soerjono Soekanto, Pengantar Penelitian Hukum, (Jakarta: UI Press, 1986), h. 9-10.

Syuhudi Ismail, Metodologi Penelitian Hadis, (Jakarta: Bulan Bintang, 1992), h. 63. 
Batas Minimal Mahar (Kajian Komparasi Antara Pendapat Mazhab Hanafi Dan Mazhab Syafi'i)

Vol. 5 No. 2 Oktober 2019

Halaman $131-150$ 